\title{
Kinetics of Oxygen Refining Process for Ferromanganese Alloys
}

\author{
Young E. LEE and Leiv KOLBEINSEN ${ }^{11}$ \\ SINTEF Materials and Chemistry, Alfred Getzv 2, N-7034 Trondheim, Norway. \\ 1) Norwegian University of Science and Technology, Alfred Getzv 2, N-7491 Trondheim, Norway.
}

(Received on April 1, 2005; accepted on June 15, 2005)

\begin{abstract}
The present analysis of the experimental data by Yamamoto et al. permitted to determine the rate controlling mechanisms for the decarburization and evaporative manganese loss concurrently taking place during the oxygen refining process of ferromanganese melt.

When oxygen is supplied by a top lance blowing mode, the decarburization reaction takes place by three different mechanisms in sequence. The chemical reaction at the melt-gas interface controls the rate of decarburization during the first period, the rate of oxygen supply through the boundary layer in gas during the second period, and the mass transfer rate of carbon in melt during the third period when the carbon content is less than 2 mass \%.

Manganese is lost primarily by evaporative reaction, but its dynamics are affected by the prevailing excess oxygen after accounting for $\mathrm{CO}$ formation. The excess oxygen and manganese vapor establish counter-current flux and form $\mathrm{MnO}$ mist at some distance away from the metal-gas interface. This creates two diffusion boundary layers, one for the flux of manganese vapor adjacent to the melt-gas interface and the other for the flux of excess oxygen in the gas phase. When the vapor pressure of manganese at the metal-gas interface is low, the rate of manganese vapor loss is controlled by the flux of excess oxygen. Otherwise, it is determined by the flux of manganese vapor.
\end{abstract}

KEY WORDS: decarburization; kinetics; ferromanganese; oxygen refining.

\section{Introduction}

High carbon ferromanganese, which contains 7.5 mass $\%$ $\mathrm{C}$ max., 74 to 82 mass\% Mn, and 1.2 mass\% Si max., is a cost effective manganese alloy used to meet the alloying requirements in steelmaking. Refined ferromanganese alloys, which contain 1.5 mass $\% \mathrm{C}$ and less, are also developed for steel grades which demand a close control of carbon content. At present, they are prepared predominantly by oxygen refining process of high carbon ferromanganese, but the process needs to be further improved. This requires a good understanding of the mechanisms of the process.

Yamamoto et al. ${ }^{1)}$ experimentally determined the variation of carbon and manganese contents as well as temperature of ferromanganese melt under various oxygen blowing conditions and provided an insight for the mechanisms of decarburization and manganese loss. A reexamination of their data indicates that a part of manganese vapor at meltgas interface oxidizes to $\mathrm{MnO}$ in a gas phase near the boundary layer. As the effect of oxidation of manganese vapor was not considered, their interpretation may be incomplete. The present study discusses the kinetics of decarburization and evaporative manganese loss by taking into account for the formation of $\mathrm{MnO}$.

\section{Experimental Results by Yamamoto et al.}

Yamamoto et al. ${ }^{1)}$ prepared a high carbon ferromanganese alloy melt weighing $500 \mathrm{~kg}$ by an induction furnace and transferred it to an experimental converter. The initial alloy melt composition was adjusted to be about 6.8 mass $\%$ C, 76 mass $\% \mathrm{Mn}$, and 0.01 to 0.08 mass $\% \mathrm{Si}$ and the melt temperature to be about $1613 \mathrm{~K}$. Oxygen was supplied mainly by a top lance with a single Laval nozzle of $5 \mathrm{~mm}$ diameter. Argon and oxygen, if required, were injected through a tuyere placed in the bottom of the converter. With this arrangement of top lance and bottom tuyere, they examined the effect of three oxygen blowing configurations: (1) top oxygen blowing without bottom gas stirring, (2) top oxygen blowing with bottom Ar stirring, and (3) top and bottom oxygen blowing with bottom Ar stirring. Table 1 summarizes their experimental setup and conditions. They experienced a heavy loss of manganese as dust and characterized it to be $\mathrm{Mn}_{3} \mathrm{O}_{4}$.

They monitored the contents of carbon and manganese and melt temperature at three-minute intervals during the

Table 1. Experimental Conditions by Yamamoto et al.

\begin{tabular}{ll}
\hline experimental converter & $600 \mathrm{~mm}$ inner diameter \\
melt weight & $500 \mathrm{~kg}$ Ferromanganese alloy melt \\
depth of melt & $400 \mathrm{~mm}$ \\
lance height & $400-450 \mathrm{~mm}$ \\
top oxygen lance & single Laval nozzle of $5 \mathrm{~mm}$ dia.(throat) \\
bottom tuyere & double wall annular tubes with outer Ar coolant \\
gas flow rates & \\
(1) top $\mathrm{O}_{2}$ without bottom stir & top $\mathrm{O}_{2}:: 1.585 \mathrm{~m}^{3} / \mathrm{min}$ \\
(2) top $\mathrm{O}_{2}$ with bottom $\mathrm{Ar}$ stir & top $\mathrm{O}_{2} \quad: \quad 1.585 \mathrm{~m}^{3} / \mathrm{min}$ \\
& bottom Ar: $0.135 \mathrm{~m}^{3} / \mathrm{min}$ \\
(3) top and bottom $\mathrm{O}_{2}$ with Ar stir & top $\mathrm{O}_{2}: 1.39 \mathrm{~m}^{3} / \mathrm{min}$ \\
& bottom $\mathrm{O}_{2}: 0.255 \mathrm{~m}^{3} / \mathrm{min}$ \\
& bottom $\mathrm{Ar}: 0.18 \mathrm{~m}^{3} / \mathrm{min}$ \\
\hline
\end{tabular}




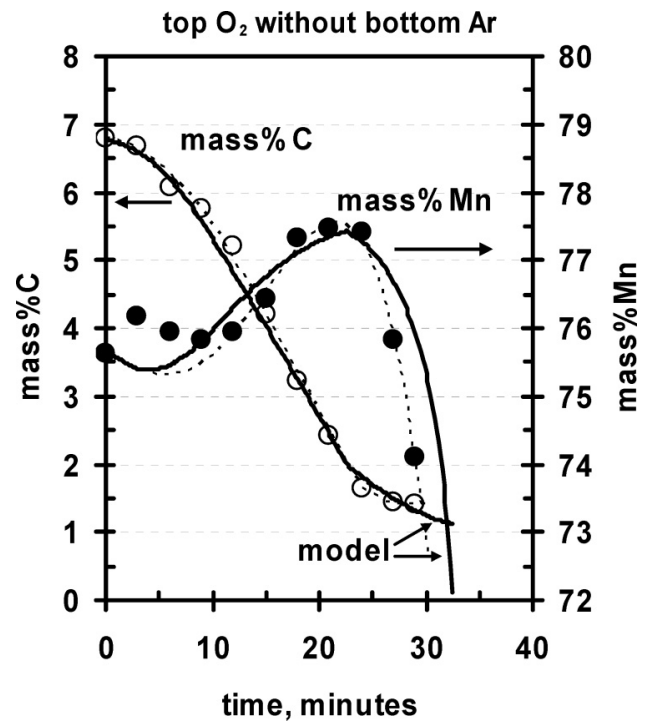

Fig. 1. Variation of carbon and manganese contents with time by top oxygen blowing without bottom Ar stirring.

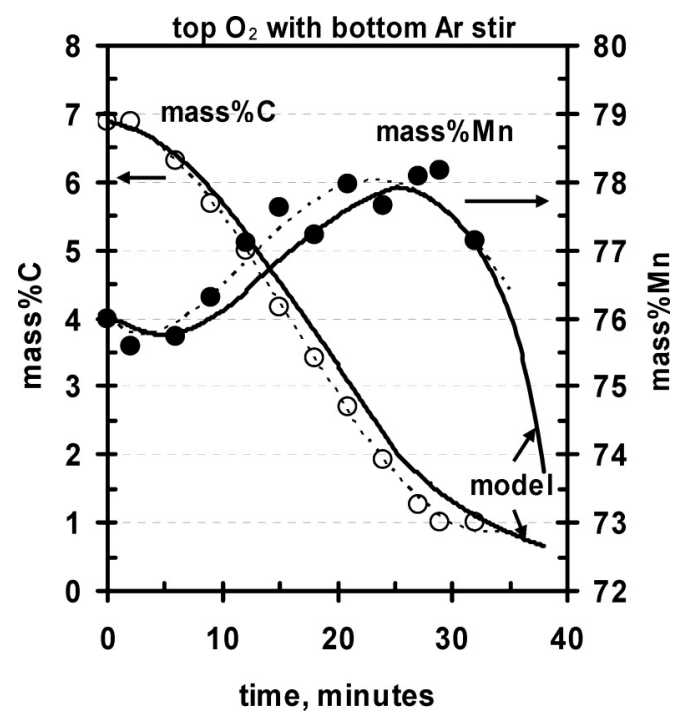

Fig. 2. Variation of carbon and manganese contents with time by top oxygen blowing with bottom Ar gas stirring.

oxygen blowing period and reported them graphically. Figures 1, 2 and 3 are the reproduction of their observed variation of carbon and manganese for three oxygen blowing configurations, and Fig. $\mathbf{4}$ is that of melt temperature. The carbon content decreases gradually during the initial period of about $10 \mathrm{~min}$. After this, the carbon content decreases linearly with time, indicating that the rate of carbon loss is independent of carbon content, until it reaches to 2 mass \% C at about 22 to $24 \mathrm{~min}$. Finally, when the carbon content becomes less than 2 mass $\%$, the rate of carbon loss becomes slower with the decrease of carbon content. The manganese content and melt temperature vary similarly with processing time. The manganese content decreases initially to its minimum and, then, return to its initial values during the initial period of about $10 \mathrm{~min}$. After that, it steadily increases to its maximum at about 22 and $24 \mathrm{~min}$ of processing time. Thereafter, it decreases quickly with time. The melt temperature increases in general with the progress of oxygen blowing, but its rate of increase changes in similar patterns with time. It increases quickly during the initial

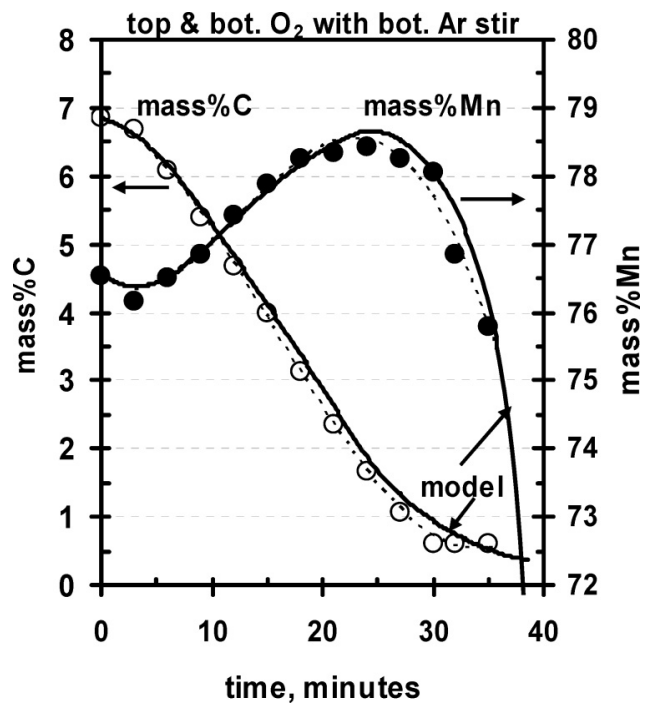

Fig. 3. Variation of carbon and manganese contents with time by top and bottom oxygen blowing with bottom Ar stirring.

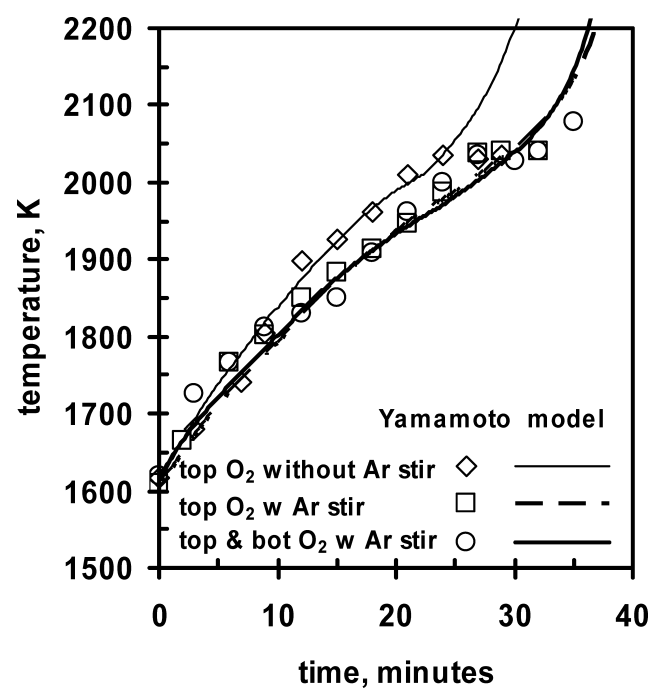

Fig. 4. Variation of melt temperature with time.

period of about $10 \mathrm{~min}$, and it continues to increase but at a steady rate until it reaches to about 22 to $24 \mathrm{~min}$. Thereafter, temperature may either level off or increase further with time. This ambiguous trend may be attributed to uncertainty in temperature measurement at high temperatures. They determined the rates of carbon and total manganese loss from their observed variation of melt compositions and reported them in mass unit $(\mathrm{kg}-\mathrm{C} / \mathrm{min}$ and $\mathrm{kg}-$ $\mathrm{Mn} / \mathrm{min}$ ) in graphic forms. Figures 5 and $\mathbf{6}$ are the reproduction of their results in the coordinate of carbon content as they reported. It shows that the rate of carbon loss gradually increases during the initial period, becomes high during the second period, and decreases during the third period. The rate of total manganese loss is high at the beginning but decreases to its minimum at the end of the initial period. Thereafter, it increases during the second through third periods.

They concluded that the decarburization takes place concurrently with evaporation of manganese and its oxidation. However, they did not elaborate the mechanisms of manganese oxidation and its effect on evaporative manganese loss. 


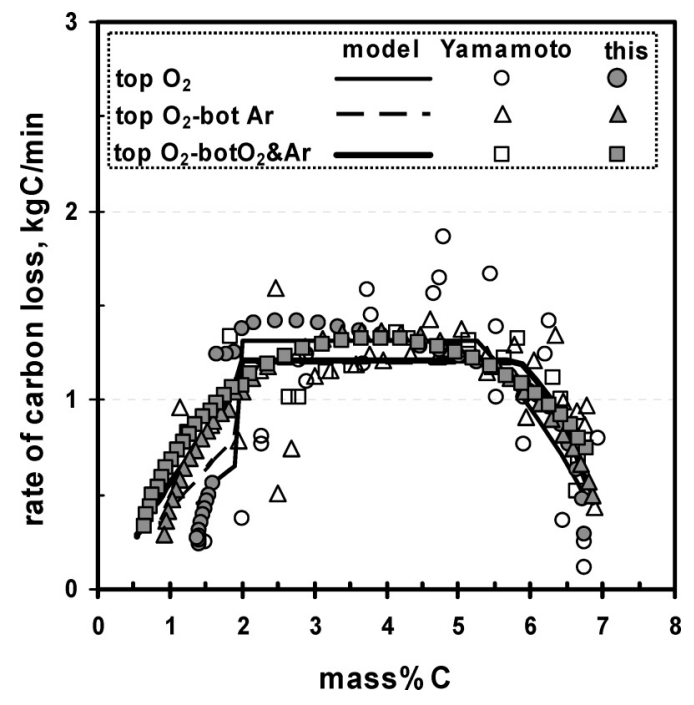

Fig. 5. Rate of carbon loss, $\mathrm{kgC} / \mathrm{min}$, at various carbon content.

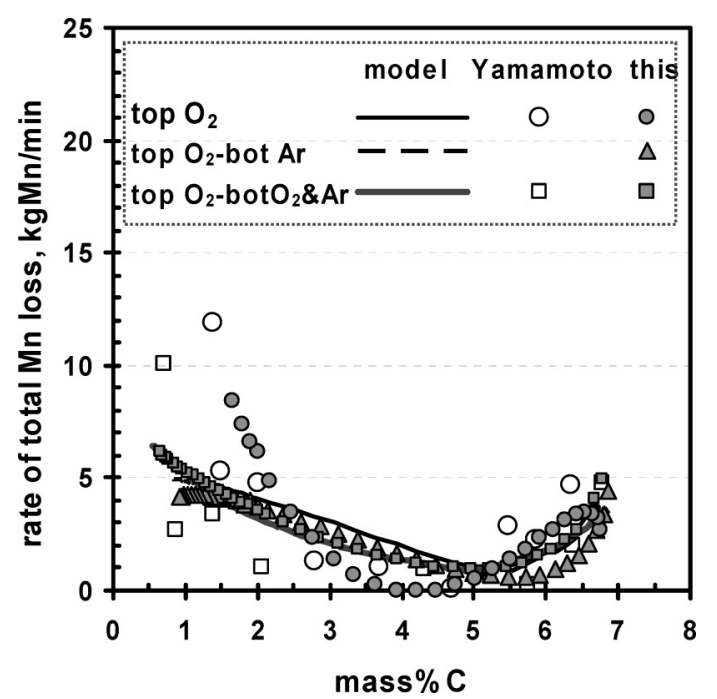

Fig. 6. Rate of total manganese loss, $\mathrm{kgMn} / \mathrm{min}$, at various carbon content.

\section{Assessment for Oxidation of Manganese}

The reaction of manganese oxidation needs to be characterized. An oxygen balance shows that excess oxygen after accounting for the formation of $\mathrm{CO}$ prevails at the melt-gas interface but it is not sufficient enough to account for all observed manganese loss as $\mathrm{Mn}_{3} \mathrm{O}_{4}$. This indicates that a portion of manganese vapor oxidizes to $\mathrm{MnO}$ at the proximity of metal-gas interface and are transported and oxidized further to $\mathrm{Mn}_{3} \mathrm{O}_{4}$ at the mouth of the reactor by entrained air. Additional information for manganese oxidation comes from the assessment of the rate of manganese oxidation. The melt temperature is determined by heat of reactions at the reaction sites. The oxidation of carbon to $\mathrm{CO}$ is exothermic, and the evaporative reaction of manganese is endothermic. The oxidation of manganese is exothermic, but its exothermicity is different whether manganese is oxidized as liquid or as vapor. Therefore, the rate of manganese loss as oxide can be determined from a heat balance. The following describes the present assessment of manganese oxidation.

For material balances, ferromanganese alloy melt is considered to be $\mathrm{Mn}-\mathrm{Fe}-\mathrm{C}$ system because of the low initial silicon content which is from 0.01 to $0.08 \mathrm{mass} \%$. Furthermore, Fe is assumed to be noble with respect to $\mathrm{Mn}$, because a consideration of the $\mathrm{FeO}$ and $\mathrm{MnO}$ exchange reaction as formulated by the following Eq. (1) indicates that $\mathrm{FeO}$ formation from a manganese rich alloy melt would be about two order of magnitude lower than $\mathrm{MnO}$ formation in the temperature range of 1873 to $2073 \mathrm{~K}$.

$$
\begin{gathered}
\mathrm{Fe}(\mathrm{l})+\mathrm{MnO}(\mathrm{s})=\mathrm{FeO}(\mathrm{l})+\mathrm{Mn}(\mathrm{l}), \\
\Delta G^{\circ}(\mathrm{J})=153050-29.65 T^{2)}
\end{gathered}
$$

When data reported at three minute intervals by Yamamoto et al. are used, the rates of carbon and total manganese losses vary with a high degree of scatter, especially for the experiment with top oxygen blowing only, and do not permit to determine a consistent set of rate constants. Another problem is an apparent inconsistency in variation of manganese content during the initial period for the experiment with top oxygen blowing only. Unlike the other two blowing configurations, the experiment by top oxygen blowing only shows manganese contents during the initial period of 6 to $9 \mathrm{~min}$ higher than the initial manganese content. When these higher values are used, the calculated weight of ferromanganese alloy melt becomes higher than the original weight $(500 \mathrm{~kg})$. This behavior is attributed to possible sampling errors. In order to overcome these problems, polynomial equations were developed to reproduce their experimentally determined variation of carbon and manganese contents and temperature as closely as possible in the pattern discussed in Sec. 2 and used to interpolate their data to read them more frequently than three minutes interval. The reassessed results closely reproduce the experimental data by Yamamoto et al. as shown dotted lines in Figs. 1, 2, and 3. These reproductions were used to determine the rates of carbon and total manganese losses at one minute interval. Figures 5 and 6 compare the reassessed rates of carbon and total manganese losses (data in grey color) favorably with those by Yamamoto et al. A noticeable difference is that the rate of carbon loss by Yamamoto et al. shows a wide scattering during the second period while that by the present assessment is near to a constant value.

When a heat balance is made using thermochemical data from Pankratz ${ }^{2}$ and Kelley, ${ }^{3)}$ the melt temperature determined by Yamamoto et al. is reproduced best when total manganese loss is considered to take place as manganese vapor and a portion of it to be oxidized to $\mathrm{MnO}$. Figure 7 shows the variation of the rate of total manganese loss and its loss as $\mathrm{MnO}$ for three blowing configurations. The rates of $\mathrm{Mn}$ loss as $\mathrm{MnO}$ are less than those of total manganese loss at a given processing time but follow the same trend of total manganese loss. This indicates that the vaporization of manganese is responsible for the observed total manganese loss and a portion of it is oxidized to $\mathrm{MnO}$ in gas boundary region near the interface of melt and gas.

\section{Discussion}

The decarburization reaction determines the processing time and affects the slag forming reaction with a conse- 


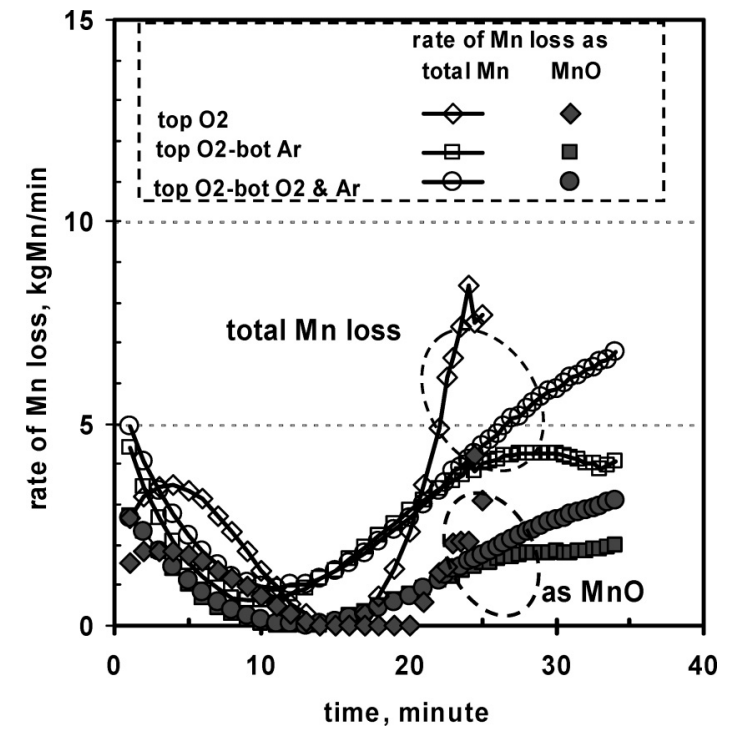

Fig. 7. Rates of total $\mathrm{Mn}$ loss and as $\mathrm{MnO}$ with processing time.

quence of manganese yield. The refining reactions take place between alloy melt and gas across the interface. When it contacts a manganese alloy melt, oxygen initially reacts with $\mathrm{Mn}$ to form $\mathrm{MnO}$ due to its relative abundance to carbon, but the formation of $\mathrm{FeO}$ is negligibly small as mentioned in the Sec. 3. Then, carbon in the alloy melt transfers to the interface and reduces $\mathrm{MnO}$. As mentioned in the Sec. 3, the evaporative loss of manganese accounts for the total observed manganese loss. In the absence of silica formation, therefore, the net reaction is the oxidation of carbon with a negligible residual $\mathrm{MnO}$ after carbon oxidation reaction as long as carbon transfers quickly to the interface. This is the case during the initial and second refining periods. When the transfer of carbon becomes slow, the residual $\mathrm{MnO}$ will accumulate during the third period. However, the presently available experimental data are not sufficient to quantify the rate of formation of the residual $\mathrm{MnO}$, and the present assessment was made with an assumption of slag free reactions. This is justified also because a combined duration of the initial and second periods is about $75 \%$ of total refining time.

\subsection{Interfacial Areas}

For top oxygen blowing configuration, the refining reaction is considered to take place over the entire area of melt surface, and the cross section area of the vessel, $0.2826 \mathrm{~m}^{2}$, is taken as that for the interface. For bottom injected oxygen, the refining reactions take place across interfacial area between submerged gas bubbles and melt. Unless the kinetics is controlled by mass transfer in gas, the area for submerged bubbles may be estimated from the rates of decarburization. The rate of decarburization during the initial period is not controlled by mass transfer in gas as discussed in the followings. The difference in the observed rates of carbon loss between two top oxygen blowing configurations and the top oxygen blowing with bottom oxygen injection is attributed to the interfacial area of bubbles. This method determines the interfacial area of submerged bubbles to be $0.0487 \mathrm{~m}^{2}$.

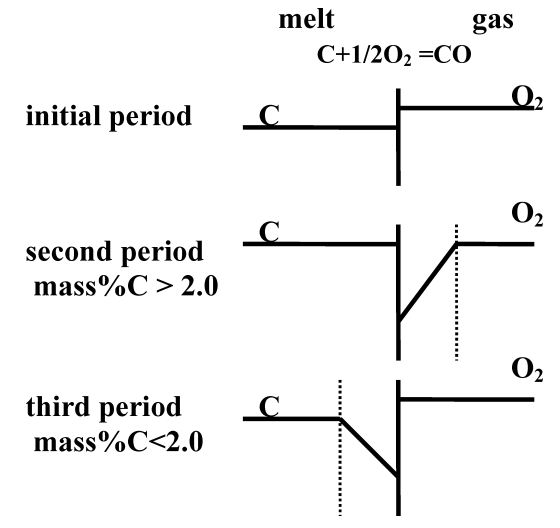

Fig. 8. Schematic representation of concentration profiles of carbon in melt and of oxygen in gas during three periods of decarburization.

\subsection{Rate Controlling Mechanisms for Decarburization}

The decarburization takes place by the oxidation of carbon in ferromanganese melt to form $\mathrm{CO}$ at the interface of melt and gas. The content of carbon is high initially but decreases in three different patterns with time, while oxygen is supplied at a high but steady rate for the entire duration of the refining process. The possible rate-limiting factors for decarburization are the chemical reaction at the interface, mass transfer rate of oxygen through a boundary layer in gas, and that of carbon through a boundary layer in melt. As indicated in Sec. 2, the decarburization takes place by three different mechanisms in sequence. Figure $\mathbf{8}$ is a schematic representation of these three rate-controlling mechanisms that sequentially prevail during each refining period. During the initial period, the carbon content maintains at a high level in melt. Both mass transfer rates of carbon and oxygen are sufficiently high enough that the chemical reaction at interface is considered to be the rate limiting factor. The rate of carbon loss during the second period is independent of carbon content. This indicates that carbon is oxidized only at the rate that oxygen is transferred to the interface. During the third period when the carbon content is less than 2 mass $\%$, the rate of carbon loss decreases with decreasing carbon content. This suggests that the carbon contents during the third period are below the critical value, 2 mass $\% \mathrm{C}$, and that the mass transfer of carbon to the interface is not sufficiently high enough to react with all supplied oxygen.

\subsection{Kinetics of Decarburization during the Initial Pe- riod}

During the initial period, the rate of carbon loss and melt temperature increase with the processing time. Indications are that the rate of carbon loss is controlled by the chemical reaction of $\mathrm{C}$ with oxygen to form $\mathrm{CO}$ at the interface:

$$
\underline{\mathrm{C}}+1 / 2 \mathrm{O}_{2}=\mathrm{CO} \text {. }
$$

where the under line indicates carbon in solution of manganese alloy melt. Neglecting the reverse reaction, its kinetics is taken to be the first order with respect to carbon, and the rate of carbon loss is represented in mass unit by the Eq. (3).

$$
-\frac{d W_{\mathrm{C}}}{d t}=k_{\mathrm{C} 1} A \frac{\rho}{100}[\text { mass } \% \mathrm{C}]
$$




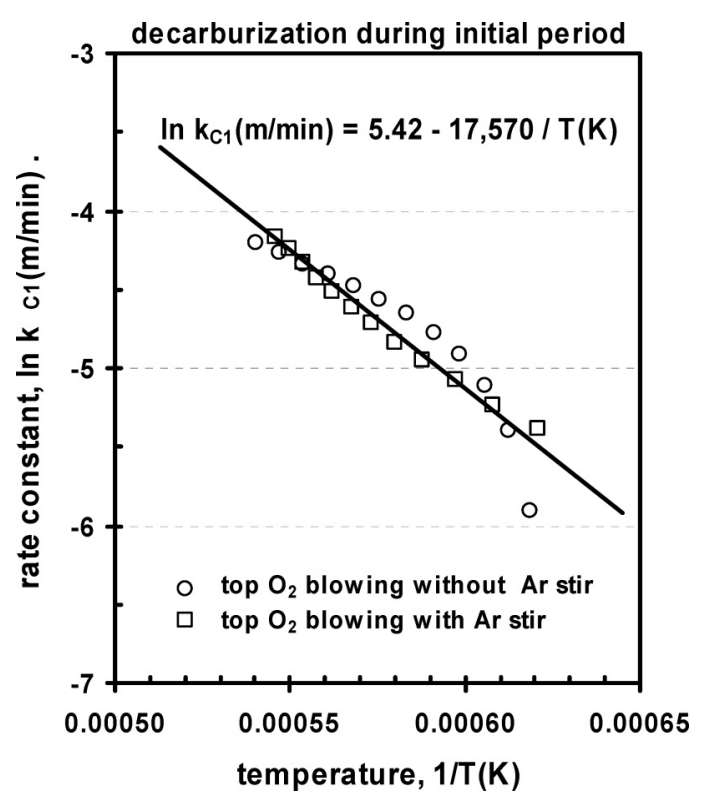

Fig. 9. The rate constant for decarburization during the initial period.

where $W_{\mathrm{C}}$ is the weight of carbon loss in $\mathrm{kgC}, t$ time in minute, $k_{\mathrm{C} 1}(\mathrm{~m} / \mathrm{min})$ the rate constant, $A\left(\mathrm{~m}^{2}\right)$ the interfacial area, $\rho\left(\mathrm{kg} / \mathrm{m}^{3}\right)$ density of ferromanganese alloy melt, and mass $\% \mathrm{C}$ carbon content of the melt. The density of ferromanganese alloy melt is calculated by the ideal molar volume method. ${ }^{4)}$

The rate constant, $k_{\mathrm{C} 1}$, is determined by correlating the observed rates of carbon loss with mass per cent of carbon during the initial period of $10 \mathrm{~min}$ from the data with two top oxygen blowing configurations with and without bottom Ar stirring. As shown in Fig. 9, the rate constant increases with temperature. Its relationship with temperature is approximated by the Eq. (4).

$$
\ln k_{\mathrm{C} 1}=5.42-17570 / T(\mathrm{~K}) \text {. }
$$

\subsection{Kinetics of Decarburization during the Second Pe- riod}

The rate of carbon loss during the second period is only fast enough to balance the rate of oxygen supply to the interface, and the flux of oxygen to the interface is observed to be less than the bulk oxygen supply rate. The phenomena of oxygen mass transfer are considered by two methods.

\subsubsection{Oxygen Balance Method}

The rate of carbon loss is considered to be proportional to the bulk oxygen supply rate as shown by the Eq. (5).

$$
-\frac{d W_{\mathrm{C}}}{d t}=f\left[\frac{24}{22.4}\right] Q_{\mathrm{O}_{2}}
$$

or

$$
-\frac{d(\mathrm{mass} \% \mathrm{C})}{d t} f\left[\frac{24}{22.4}\right] \cdot 100 Q_{\mathrm{SPO}_{2}}
$$

where $Q_{\mathrm{O}_{2}}\left(\mathrm{~m}^{3}-\mathrm{O}_{2} / \mathrm{min}\right)$ and $Q_{\mathrm{SPO}_{2}}\left(\mathrm{~m}^{3}-\mathrm{O}_{2} / \mathrm{kg}\right.$-min $)$ are the oxygen flow rate and specific oxygen flow rate, respectively, and $f$ is a measure of efficiency of the supplied oxygen for decarburization reaction. This is the same expression pro-

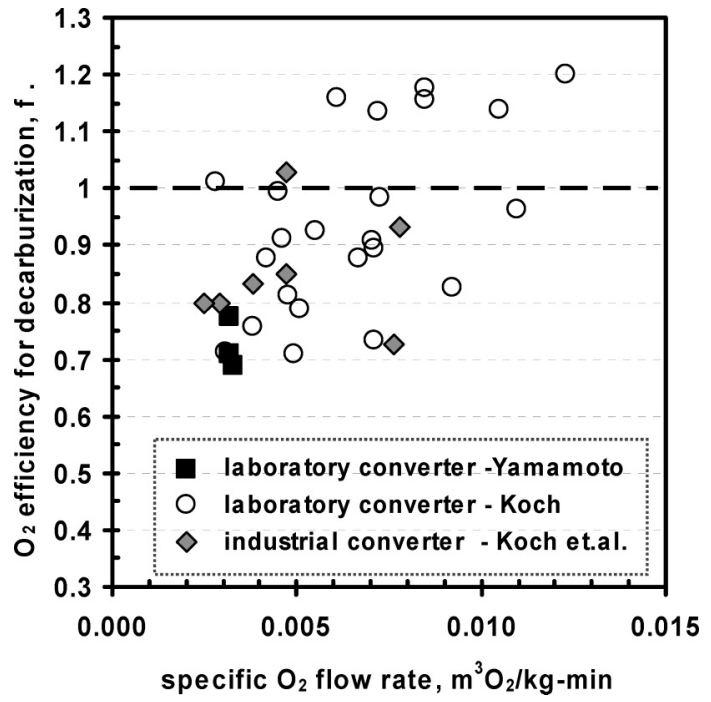

Fig. 10. Oxygen efficiency of decarburization during the second period for top oxygen injection converter.

posed by Fruehan. ${ }^{5)}$

The efficiency, $f$, is assumed to be constant for a given oxygen blowing configuration, although this may not be an accurate assessment for the submerged gas bubbles. The reassessed data in Fig. 5 show that the rate of carbon loss during the second period is close to but not quite a constant value. In order to reconcile this discrepancy, the total amount of carbon lost until 2 mass $\% \mathrm{C}$ was calculated by integrating the carbon loss from the re-assessed data in Fig. 5. The amount of carbon lost, and the rate of carbon loss, during the second period only, then, was obtained by subtracting the accumulated carbon loss during the initial period. Thus estimated efficiencies of oxygen, $f$, are 0.773 for top oxygen without Ar stirring, 0.708 for top oxygen with bottom Ar stirring, and 0.689 for top and bottom oxygen blowing with bottom Ar stirring. These are used to reproduce the experimental results.

Koch et al. ${ }^{6)}$ examined the effect of oxygen flow rate on the decarburization of iron melt for the period when the carbon content decreases linearly with time. Their assessment of data from laboratory experiments as well as industrial operations shows that the rate of decarburization increases with increasing oxygen flow rate. A set of their data for top oxygen blowing configuration was modified to correlate the oxygen efficiency to the oxygen flow rate as shown in Fig. 10. Some of their data show the oxygen efficiency to be higher than 1.0. These are attributed to poor quality of data. The rest show that the oxygen efficiency increases with increasing oxygen flow rate. Especially, the oxygen efficiencies from the works of Yamamoto et al. follow the same trend. This agreement suggests that the rate of decarburization for both iron and manganese alloy melts are controlled by the same mechanism.

\subsubsection{Mass Transfer Method}

After Swisher and Turkdogan, ${ }^{7}$ the rate of carbon loss is equated to the flux of oxygen through the diffusion boundary layer in gas phase. 


$$
-\frac{d n_{\mathrm{C}}(\mathrm{molC})}{d t}=\frac{1}{2} J_{\mathrm{O}_{2}} A=A \frac{m}{2 R T} \ln \left(1+P_{\mathrm{O}_{2}}\right)
$$

where $m$ is the mass transfer coefficient, $A$ the interfacial area, $R$ the gas constant, and $P_{\mathrm{O}_{2}}$ oxygen pressure in bulk gas phase. The mass transfer coefficients, $m(\mathrm{~m} / \mathrm{min})$, were determined at the averaged temperature of $1923 \mathrm{~K}$ $\left(1650^{\circ} \mathrm{C}\right)$ during the second period for two top oxygen blowing configurations with and without Ar stirring. They are 161 and $176 \mathrm{~m} / \mathrm{min}$, respectively.

Taniguchi et al. ${ }^{8)}$ characterized the mass transfer phenomena for the vertically injecting gas jet. When the ratio of $H$ to $d(H / d)$, where $H$ is the lance height above the melt surface and $d$ inner diameter of lance nozzle, is less than the critical value, $(H / d)_{c}$, they found that the averaged Sherwood number is independent of $H / d$ ratio but increases with increasing Reynolds number. They proposed the Eq. (7) to define the mass transfer phenomena for the decarburization of iron melt.

$$
\mathrm{Sh}=0.23\left(d / r_{\mathrm{s}}\right) \operatorname{Re}^{0.66} \mathrm{Sc}^{0.5}
$$

where Sh is Sherwood number, Re Reynolds number, and Sc Schmidt number. Yamamoto et al. carried out the experiment with the $H / d$ ratio less than the critical value. The calculated value for $\mathrm{m}$ is about $44(\mathrm{~m} / \mathrm{min})$ at $1923 \mathrm{~K}$ for their top oxygen blowing configuration with the cross section area of the vessel as the interface. This is less than the observed values of 161 and $176 \mathrm{~m} / \mathrm{min}$. However, this lower calculated value does not invalidate their assessment. When the interfacial area is reduced to $0.023 \mathrm{~m}^{2}$, which is an impact area for a jet with $12^{\circ}$ spread, the calculated mass transfer coefficient at $1923 \mathrm{~K}$ becomes $154 \mathrm{~m} / \mathrm{min}$. The assumed interfacial area for top blowing oxygen may not be accurate. A detail examination is beyond the scope of the present analysis and deferred to a future study.

\subsection{Kinetics of Decarburization during the Third Pe- riod}

During the third period where carbon content is less than 2 mass $\% \mathrm{C}$, the rate of carbon transfer from melt is not fast enough to react with all supplied oxygen. The rate of carbon loss in this case is given by the following Eq. (8) in mass unit.

$$
\frac{d(\operatorname{mass} \% \mathrm{C})}{d t}=-A k_{\mathrm{C} 3} \frac{\rho}{W T}\left[\operatorname{mass} \% \mathrm{C}-\operatorname{mass}_{0} \mathrm{C}_{\mathrm{e}}\right] \ldots
$$

where $A\left(\mathrm{~m}^{2}\right)$ is the interfacial area, $k_{\mathrm{C} 3}(\mathrm{~m} / \mathrm{min})$ the mass transfer coefficient, $\rho\left(\mathrm{kg} / \mathrm{m}^{3}\right)$ density of ferromanganese melt, $W T(\mathrm{~kg})$ the weight of ferromanganese melt, and mass $\% \mathrm{C}$ and $\operatorname{mass} \% \mathrm{C}_{\mathrm{e}}$ are the carbon content at time $t$ and equilibrium, respectively. The equilibrium carbon content is small and neglected. The weight and density of ferromanganese melt below the critical carbon content were calculated, and their averaged values were used for the present assessment.

The mass transfer coefficient, $k_{\mathrm{C} 3}$, was determined by correlating the experimentally determined carbon content, $\ln (\operatorname{mass} \% \mathrm{C})$, with time after 2 mass $\% \mathrm{C}$. The results are shown in Fig. 11 and summarized in the followings:

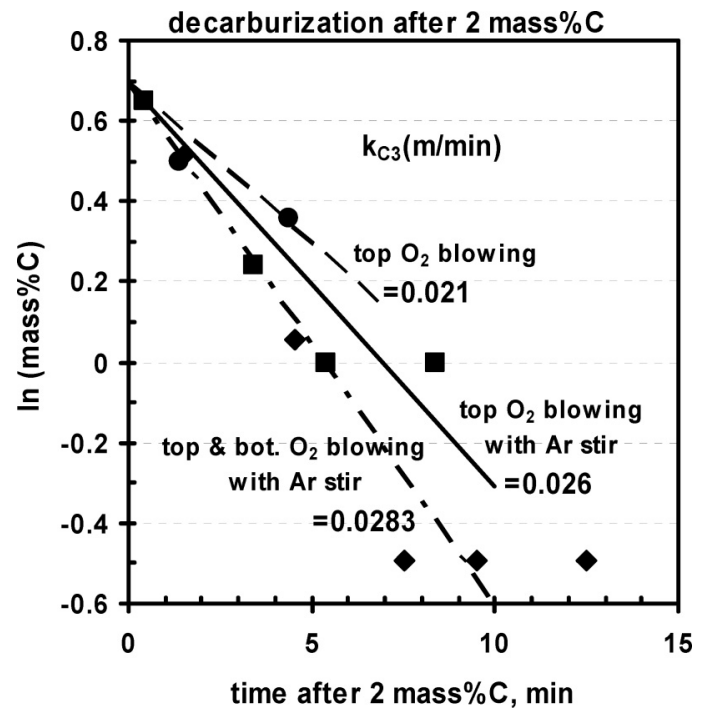

Fig. 11. Mass transfer coefficient of carbon during the third period.

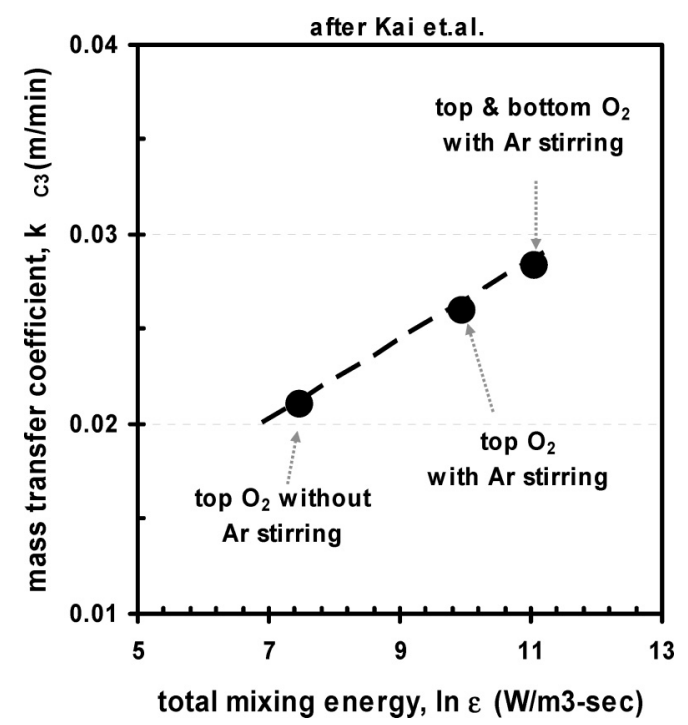

Fig. 12. Effect of mixing intensity of melt on mass transfer coefficient of carbon.

oxygen blowing configuration $\quad A\left(\mathrm{~m}^{2}\right) \quad W T(\mathrm{~kg}) \rho\left(\mathrm{kg} / \mathrm{m}^{3}\right) k_{\mathrm{C} 3}(\mathrm{~m} / \mathrm{min})$

\begin{tabular}{lllll}
\hline top $\mathrm{O}_{2}$ blowing & 0.2826 & 409 & 5527 & 0.021 \\
$\begin{array}{l}\text { top } \mathrm{O}_{2} \text { blowing with } \\
\text { bottom Ar stirring }\end{array}$ & 0.2826 & 407 & 5536 & 0.026 \\
$\begin{array}{l}\text { top and bottom } \mathrm{O}_{2} \\
\text { with Ar stirring }\end{array}$ & 0.3313 & 400 & 5543 & 0.0283 \\
\end{tabular}

The mass transfer coefficient, $k_{\mathrm{C} 3}$, is shown to increase when $\mathrm{Ar}$ gas or $\mathrm{Ar}-\mathrm{O}_{2}$ mixture was injected through a bottom tuyere. This increase is due to an increased mixing intensity of melt by bottom injected gas. The mixing energy of melt under the experimental condition by Yamamoto et al. was calculated by the equation of Kai et al. ${ }^{9}{ }^{9}$ Figure 12 shows that the mass transfer coefficients correlate very well with the calculated mixing energy. The excellent correlation may be fortuitous. The calculated rates of carbon loss by the present model are compared favorably with those by Yamamoto et al. in Fig. 5. 


\subsection{Rate Controlling Mechanisms for Manganese Loss}

The experimental evidence shows that the evaporative reaction of manganese from the melt surface is responsible for the observed total manganese loss. The possible ratelimiting factors are the evaporation reaction of manganese at the interface, mass transfer rate of manganese in melt, and that of manganese vapor in gas. Because of high refining temperature, the evaporation reaction of manganese is fast. Also, its relative abundance in comparison to other elements is not likely to cause a depletion of manganese at melt surface. Therefore, the rate of evaporative manganese loss is considered to be controlled by the transfer rate of manganese vapor through the boundary layer in gas.

Vapor pressure of manganese at the interface of melt and gas was calculated from the consideration of the equilibrium with manganese in ferromanganese melt.

$$
\operatorname{Mn}_{(\mathrm{l})}=\operatorname{Mn}_{(\mathrm{g})}, \quad \Delta G^{\circ}(\mathrm{J})=238245-103.95 T(\mathrm{~K})^{2)} \ldots
$$

The activity of $\mathrm{Mn}$ in ferromanganese melt was calculated with the thermodynamic model by Lee. ${ }^{10)}$ As shown in Fig. 13(a), the calculated vapor pressure of manganese increases with time because of increasing melt temperature. The flux of manganese vapor is expected to increase with time similarly. However, the experimental results show that the rate of total manganese loss begins initially at a high rate and decreases during the initial period. After a minimum at the end of the initial period, it begins to increase with time as expected from the increasing vapor pressure of manganese. Figure 13(b) highlights these behaviors. For the reason of brevity in presentation, it shows only the rate of manganese vapor loss for top oxygen blowing with bottom Ar stirring. The pattern for manganese loss during the initial period does not follow that expected from the variation of manganese vapor pressure.

The present analysis shows that the excess oxygen after accounting for the formation of $\mathrm{CO}$ prevails in gas phase near the interface of melt and gas. As shown in Fig. 13(a), the excess oxygen in partial pressure varies in a similar pattern of total manganese loss. The rate of manganese loss as $\mathrm{MnO}$ follows the same pattern. This indicates that the dynamics of mass transfer of manganese vapor are affected by the prevailing excess oxygen.

After Turkdogan et al., ${ }^{11)}$ it is considered that the excess oxygen develops a counter current flux and reacts with manganese vapor to form $\mathrm{MnO}$ mist at some distance away from the melt surface. This creates a sink for manganese vapor and oxygen with the result of establishing two diffusion boundary zones, one for manganese vapor next to the interface of melt and gas and the other for excess oxygen in bulk gas phase. Figure 14 schematically depicts these phenomena. The thickness of boundary layer for manganese vapor depends on the relative magnitude of manganese vapor pressure at the metal-gas interface to the excess oxygen in bulk gas phase. During the initial period, the manganese vapor pressure is relatively low, and the interface of $\mathrm{MnO}$ mist moves toward the melt-gas interface with the increase of the partial pressure of the excess oxygen. This enhances the rate of manganese vapor loss. Eventually, manganese oxidizes at the metal surface, and this oxidation on
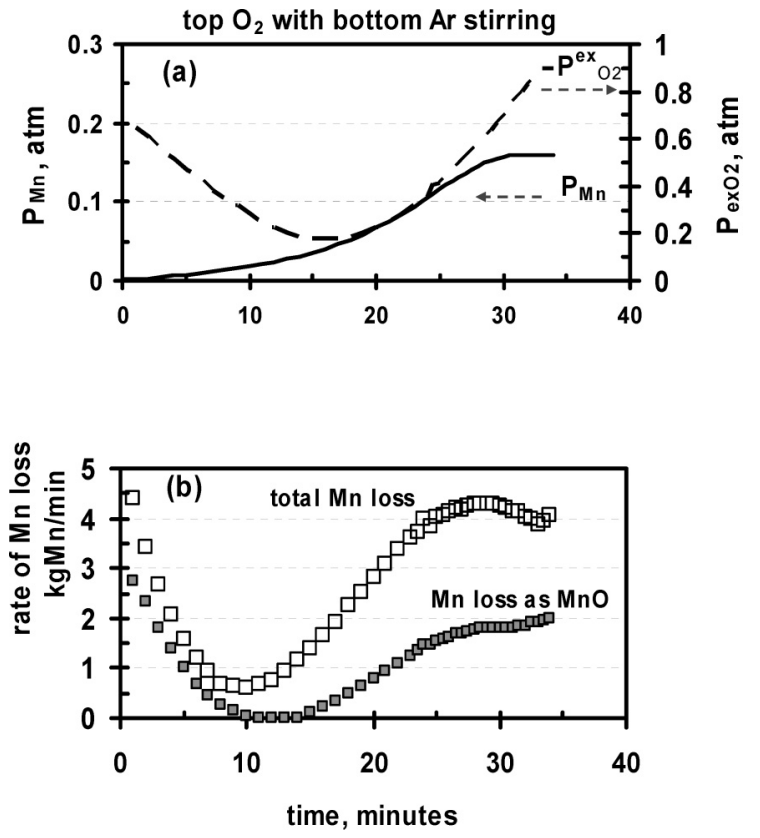

Fig. 13. Variation of (a) manganese vapor pressure and partial pressure of excess oxygen and (b) rates of total manganese loss and $\mathrm{Mn}$ loss as $\mathrm{MnO}$

$$
\text { melt gas }
$$

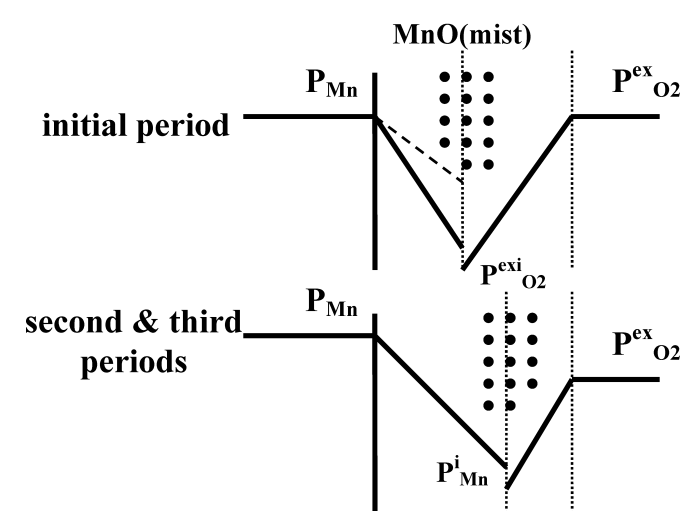

Fig. 14. Schematic representation of concentration profiles of Mn vapor and excess oxygen in gas phase during three periods of decarburization.

metal surface stops the process of manganese vaporization. Just before this cutoff, the rate of manganese vaporization is close to the maximum rate of vaporization in vacuum. This maximum rate of manganese vaporization was calculated for the three oxygen blowing configurations to be $3.01 \mathrm{kgMn} / \mathrm{min}$ for top oxygen blowing, 3.45 for top oxygen and bottom Ar stirring, and 4.50 for top and bottom oxygen with Ar stirring. The experimentally observed rates of total manganese for the first minute by Yamamoto et al. are $2.66 \mathrm{kgMn} / \mathrm{min}, 4.40$, and 4.92 , respectively. The good agreement indicates that the excess oxygen indeed enhances the rate of manganese loss. After the initial period, the manganese vapor pressure becomes high, and the rate of evaporative manganese loss is controlled by the mass transfer of manganese vapor.

\subsection{Kinetics of Manganese Losses during the Initial Period}

The rate of total manganese loss is defined by equating 
the flux of manganese vapor to the counter current flux of excess oxygen.

$$
\begin{gathered}
-J_{\mathrm{Mn}}\left(\mathrm{mol} \mathrm{Mn} / \mathrm{cm}^{2}-\mathrm{s}\right)=2 J_{\mathrm{O}_{2}} \\
=2 k_{\mathrm{O}_{2}}\left(P_{\mathrm{O}_{2}}^{\mathrm{ex}}-P_{\mathrm{O}_{2}}^{\text {exi }}\right) / R T \ldots \ldots
\end{gathered}
$$

where $k_{\mathrm{O}_{2}}$ is a mass transfer coefficient for excess oxygen, $P_{\mathrm{O}_{2}}^{\text {ex }}$ and $P_{\mathrm{O}_{2}}^{\text {iex }}$ partial pressures of excess oxygen in bulk gas phase and at the interface of two diffusion boundary layers, $R$ gas constant, and $T$ temperature in $\mathrm{K} . P_{\mathrm{O}_{2}}^{\text {exi }}$ is negligibly small. The Eq. (11) is the rate of total manganese loss in mass unit:

$$
-d W_{\mathrm{Mn}} / d t=1339 A k_{\mathrm{O}_{2}} P_{\mathrm{O}_{2}}^{\mathrm{ex}} / T \text {. }
$$

where $W_{\mathrm{Mn}}$ is total manganese loss in $\mathrm{kgMn}$ and A interfacial area in $\mathrm{m}^{2}$, and $k_{\mathrm{O}_{2}}$ a mass transfer coefficient of excess oxygen in $\mathrm{m} / \mathrm{min}$.

The experimental evidence in Fig. 13 suggests that manganese vapor does not oxidize when the excess oxygen becomes less than a minimum value. The values for the mass transfer coefficient and the minimum partial pressure of excess oxygen were determined by regression analysis of the experimental data for the initial period of $10 \mathrm{~min}$. Figure $\mathbf{1 5}$ is the result of the regression analysis, showing that the experimental data except two data points marked by $\times$ are reproduced best with the following values for the mass transfer coefficient and the minimum partial pressure of excess oxygen.

$$
\begin{gathered}
k_{\mathrm{O}_{2}}=38.3 \mathrm{~m} / \mathrm{min} \\
P_{\mathrm{O}_{2}(\min )}^{\mathrm{ex}}=0.17 \mathrm{~atm}
\end{gathered}
$$

\subsection{Kinetics of Manganese Losses during the Second and Third Periods}

The rate of total manganese loss during the second and third periods is defined by the flux of manganese vapor through a diffusion boundary layer adjacent to the interface of metal and gas.

$$
-J_{\mathrm{Mn}}\left(\mathrm{mol} \mathrm{Mn} / \mathrm{cm}^{2}-\mathrm{s}\right)=k_{\mathrm{Mn}}\left(P_{\mathrm{Mn}}-P_{\mathrm{Mn}}^{\mathrm{i}}\right) / R T \text {. }
$$

where $k_{\mathrm{Mn}}$ is the mass transfer coefficient for manganese vapor, $P_{\mathrm{Mn}}$ and $P_{\mathrm{Mn}}^{\mathrm{i}}$ vapor pressure of manganese at melt surface and the $\mathrm{MnO}$ mist interface, $R$ gas constant, and $T$ temperature. $P_{\mathrm{Mn}}^{\mathrm{i}}$ is negligibly small. The Eq. (13) is the rate of total manganese loss in mass unit:

$$
-d W_{\mathrm{Mn}} / d t=669.5 A k_{\mathrm{Mn}} P_{\mathrm{Mn}} / T
$$

where $k_{\mathrm{Mn}}$ is mass transfer coefficient in $\mathrm{m} / \mathrm{min}$ and $P_{\mathrm{Mn}}$ in atm. The mass transfer coefficient was determined by correlating the experimentally observed rates of total manganese loss during the second and third periods with vapor pressure of manganese. Because of better consistency in data as shown in Fig. 16, the regression analysis was made with the data from top oxygen with Ar stirring and top and bottom oxygen with Ar stirring. Thus determined mass transfer coefficient is as follows:

$$
k_{\mathrm{Mn}}=334 \mathrm{~m} / \mathrm{min}
$$

Figure 6 compares the calculated rate of total manganese loss using the above rate constants, $k_{\mathrm{O}_{2}}$ and $k_{\mathrm{Mn}}$, favorably with the experimental results by Yamamoto et al.

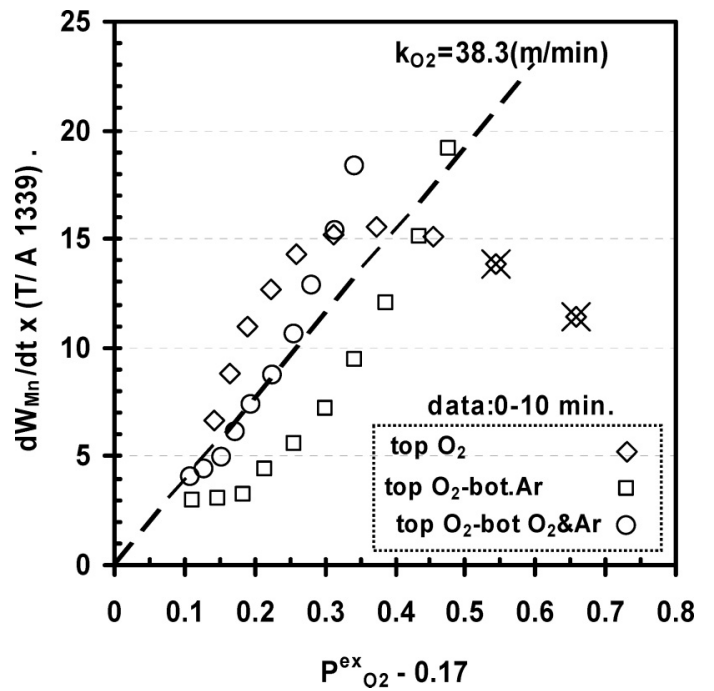

Fig. 15. Mass transfer coefficient of excess oxygen in gas phase.

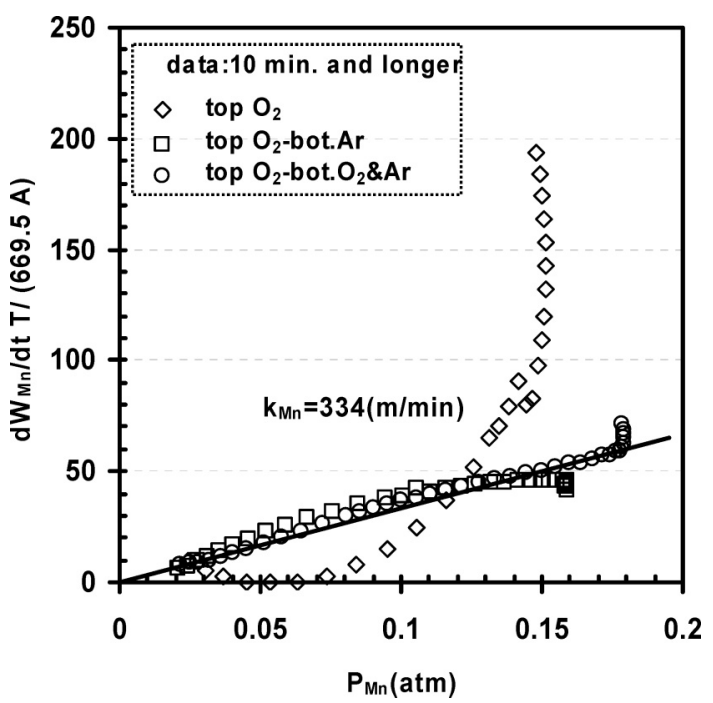

Fig. 16. Mass transfer coefficient of manganese vapor in gas phase.

\subsection{Rate of Manganese Loss as $\mathrm{MnO}$}

The formation of $\mathrm{MnO}$ mist does not proceed to its equilibrium, but its dynamic may be represented by the mass action law.

$$
\mathrm{Mn}_{(\mathrm{g})}+1 / 2 \mathrm{O}_{2}=\mathrm{MnO}, \quad Q=x_{\mathrm{MnO}} /\left[x_{\mathrm{Mn}}\left(P_{\mathrm{O}_{2}}^{\mathrm{ex}}\right)^{1 / 2}\right] \ldots
$$

where $Q$ is the quotient that defines the degree of the reaction, $x_{\mathrm{Mn}}$ and $x_{\mathrm{MnO}}$ mole fractions of $\mathrm{Mn}$ vapor and $\mathrm{MnO}$ mist, respectively, and $P_{\mathrm{O}_{2}}^{\mathrm{ex}}$ the partial pressure of the excess oxygen in gas phase after the formation of CO. As discussed above, MnO mist does not form at the partial pressure of excess oxygen less than $0.17 \mathrm{~atm}$. The amount of manganese vapor after the formation of $\mathrm{MnO}$ mist is the difference between that of total manganese loss as vapor and of $\mathrm{MnO}$ mist. The Eq. (14) is rearranged in terms of the rates of total manganese loss and manganese loss as $\mathrm{MnO}$ as shown by the following Eq. (15).

$$
\begin{aligned}
& {\left[d W_{\mathrm{MnO}} / d t\right] /\left[d W_{\mathrm{Mn}} / d t\right]} \\
& \quad=\left[Q\left(P_{\mathrm{O}_{2}}^{\mathrm{ex}}-0.17\right)^{1 / 2}\right] /\left[1+Q\left(P_{\mathrm{O}_{2}}^{\mathrm{ex}}-0.17\right)^{1 / 2}\right]
\end{aligned}
$$

where $W_{\mathrm{MnO}}$ is the manganese loss as $\mathrm{MnO}$ mist in $\mathrm{kgMn}$. 


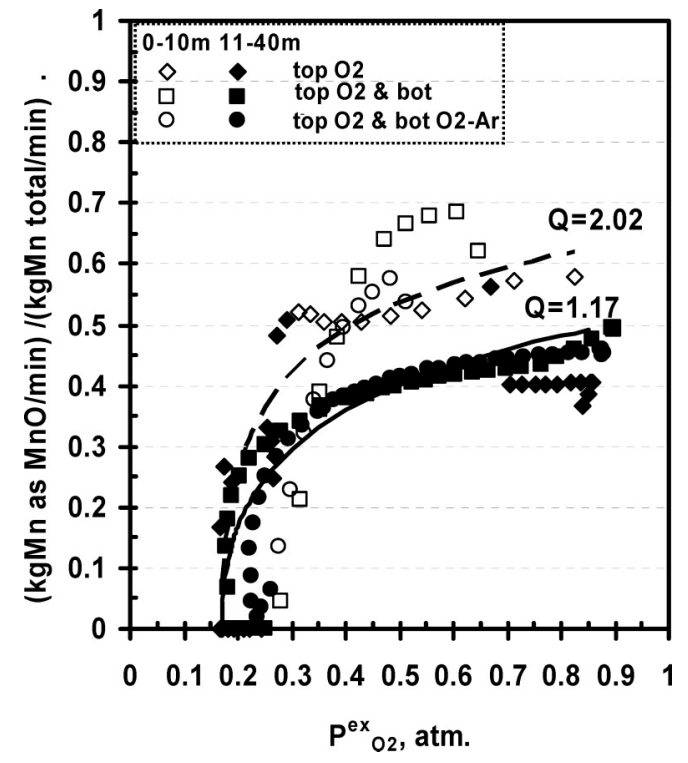

Fig. 17. Rate of manganese loss as $\mathrm{MnO}$.

The quotient, $Q$, was determined by correlating the experimentally determined ratio of manganese loss as $\mathrm{MnO}$ to total manganese loss with the partial pressure of excess oxygen. As shown in Fig. 17, the formation of $\mathrm{MnO}$ mist is described best by two quotients, one for the initial period and the other for the period thereafter.

$$
\begin{aligned}
& Q=2.02 \quad \text { during the initial period } \\
& Q=1.17 \text { during the second and third periods }
\end{aligned}
$$

As shown in Figs. 1 through 4, the present models reproduce favorably the variation of carbon and manganese contents and melt temperature by Yamamoto et al. It suggests that the melt temperature during the third period continues to increase with the oxidation of manganese vapor to $\mathrm{MnO}$.

\section{Conclusion}

The decarburization of ferromanganese alloy melt takes place by three different mechanisms in sequence, the rate controlled by chemical reaction during the initial period, by mass transfer of oxygen in gas during the second period, and by mass transfer of carbon in melt during the third period. The flux of oxygen throughout entire refining period is less than the bulk oxygen flow rate. This excess oxygen after accounting for the formation of $\mathrm{CO}$ affects the dynamics of evaporative manganese loss by a formation of $\mathrm{MnO}$ mist. Manganese is lost by evaporative mechanism. During the initial period of decarburization when the manganese vapor pressure is low, the rate of manganese loss is enhanced by the excess oxygen. When the manganese vapor pressure becomes high during the second and third periods, the rate of manganese loss is controlled by the mass transfer of manganese vapor through diffusion boundary layer adjacent to the interface of melt and gas. The formation of $\mathrm{MnO}$ mist increases the melt temperature.

\section{REFERENCES}

1) K. Yamamoto, T. Mimura, S. Ito and T. Onoye: Proc. of 4th JapanNordic Countries Joint Symp. on Sci. and Tech. of Process Metallurgy, ISIJ, Tokyo, (1986), 299.

2) L. B. Pankratz: Thermodynamic Properties of Elements and Oxides, US Bureau of Mines Bulletin 672, US Dept. of Interior, (1982).

3) K. K. Kelley: Contributions to the Data on Theoretical Metallurgy, US Bureau of Mines Bulletin 584, US Dept. of the Interior, (1960).

4) Y. E. Lee: unpublished works, ideal volume method to determine density of alloy melts.

5) The Making, Shaping and Treating of Steel, 11th addition, Steelmaking and Refining Volume, ed. by R. J. Fruehan, AISE Steel Foundation, Pittsburgh, PA, (1998), 123, 496, 715.

6) K. Koch, W. Fix and P. Valentin: Arch. Eisenhüttenwes., 49 (1978), 231.

7) J. H. Swisher and E. T. Turkdogan: Trans. Metall. Soc. AIME, 239 (1967), 602.

8) S. Taniguchi, A. Kikuchi and S. Maeda: Tetsu-to-Hagané, 62 (1976), 191.

9) T. Kai, K. Okohira, M. Hirai, S. Murakami and N. Sato: Tetsu-toHagané, 68 (1982), 1946.

10) Y. Lee: ISIJ Int., 43 (2003), 144.

11) E. T. Turkdogan, P. Grieveson and L. S. Darken: J. Phys. Chem., 67 (1963), 1647. 